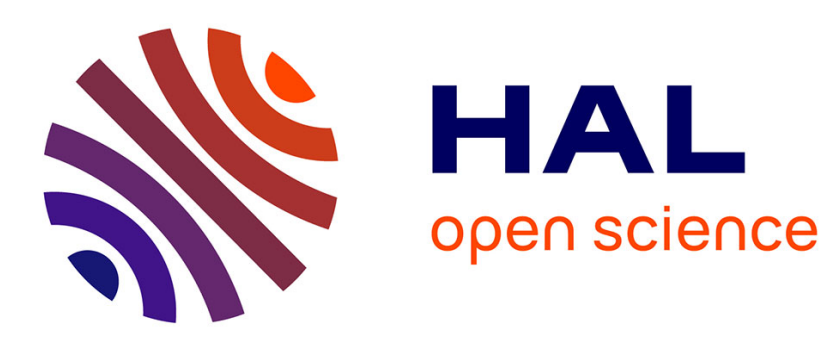

\title{
Outcome of Intralesional Curettage for Low-Grade Chondrosarcoma of Long Bones
}

\author{
S.A. Hanna, P. Whittingham-Jones, M.D. Sewell, R.C. Pollock, J.A. Skinner,
} A. Saifuddin, A. Flanagan, S.R. Cannon, T.W.R. Briggs

\section{- To cite this version:}

S.A. Hanna, P. Whittingham-Jones, M.D. Sewell, R.C. Pollock, J.A. Skinner, et al.. Outcome of Intralesional Curettage for Low-Grade Chondrosarcoma of Long Bones. EJSO - European Journal of Surgical Oncology, 2009, 35 (12), pp.1343. 10.1016/j.ejso.2009.06.001 . hal-00556313

\section{HAL Id: hal-00556313 https://hal.science/hal-00556313}

Submitted on 16 Jan 2011

HAL is a multi-disciplinary open access archive for the deposit and dissemination of scientific research documents, whether they are published or not. The documents may come from teaching and research institutions in France or abroad, or from public or private research centers.
L'archive ouverte pluridisciplinaire HAL, est destinée au dépôt et à la diffusion de documents scientifiques de niveau recherche, publiés ou non, émanant des établissements d'enseignement et de recherche français ou étrangers, des laboratoires publics ou privés. 


\section{Accepted Manuscript}

Title: Outcome of Intralesional Curettage for Low-Grade Chondrosarcoma of Long Bones

Authors: S.A. Hanna, P. Whittingham-Jones, M.D. Sewell, R.C. Pollock, J.A. Skinner, A. Saifuddin, A. Flanagan, S.R. Cannon, T.W.R. Briggs

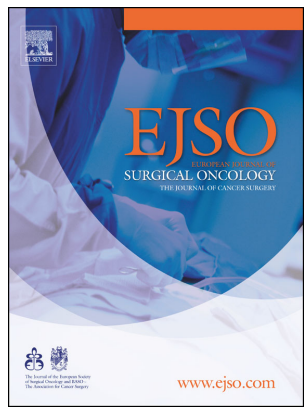

PII:

S0748-7983(09)00178-4

DOI:

10.1016/j.ejso.2009.06.001

Reference: YEJSO 2845

To appear in: European Journal of Surgical Oncology

Received Date: 29 March 2009

Revised Date: 30 May 2009

Accepted Date: 2 June 2009

Please cite this article as: Hanna SA, Whittingham-Jones P, Sewell MD, Pollock RC, Skinner JA, Saifuddin A, Flanagan A, Cannon SR, Briggs TWR. Outcome of Intralesional Curettage for LowGrade Chondrosarcoma of Long Bones, European Journal of Surgical Oncology (2009), doi: 10.1016/ j.ejso.2009.06.001

This is a PDF file of an unedited manuscript that has been accepted for publication. As a service to our customers we are providing this early version of the manuscript. The manuscript will undergo copyediting, typesetting, and review of the resulting proof before it is published in its final form. Please note that during the production process errors may be discovered which could affect the content, and all legal disclaimers that apply to the journal pertain. 


\section{Outcome of Intralesional Curettage for Low-Grade Chondrosarcoma of Long Bones}

SA Hanna ${ }^{1}$

P Whittingham-Jones ${ }^{1}$

MD Sewell ${ }^{1}$

RC Pollock ${ }^{1}$

JA Skinner ${ }^{1}$

A Saifuddin ${ }^{2}$

A Flanagan ${ }^{3}$

SR Cannon ${ }^{1}$

TWR Briggs $^{1}$
MRCS

MRCS

MRCS

FRCS (Orth)

FRCS (Orth)

FRCR, MRCP

PhD, FRCPath

MCh (Orth), FRCS

MD (Res) MCh (Orth)

FRCS
Consultant Orthopaedic Surgeon

Consultant Radiologist

Consultant Orthopaedic Surgeon

Specialist Orthopaedic Registrar

Specialist Orthopaedic Registrar

Consultant Orthopaedic Surgeon

Professor in Histopathology

Consultant Orthopaedic Surgeon 
${ }^{1}$ Department of Orthopaedic Oncology

2 Department of Radiology

${ }^{3}$ Department of Histopathology

London Bone and Soft Tissue Sarcoma Service

Royal National Orthopaedic Hospital, Stanmore

HA7 4LP, United Kingdom

Corresponding Author:

MrSA Hanna MRCS

Royal National Orthopaedic Hospital

Stanmore, Middlesex, HA7 4LP

Tel: $\quad 02089542300$, Ext: 5678

Fax: $\quad 02089095709$

Email: sammyhanna@ hotmail.com

Outcome of Intralesional Curettage for Low-Grade for Chondrosarcoma of Long Bones

\section{Abstract}


Background: Different treatment strategies for low-grade chondrosarcomas are reported in the literature with variable outcomes. The aim of this study was to assess the oncological and functional outcomes associated with intralesional curettage and cementation of the lesion as a treatment strategy.

Patients and Methods: We performed a retrospective review of 39 consecutive patients with intramedullary low-grade chondrosarcoma of long bones treated by intralesional curettage and cementation at our institution between 1999 and 2005.

Results: There were 10 males and 29 females with a mean age of 55.5 years ( 32 to 82 ), and a mean follow-up of 5.1 years ( 3 to 8.7 ). Local recurrence occurred in two patients $(5 \%)$ within the first two years following index surgery. Both were treated by re-curettage and cementation of the resultant defects. A second local recurrence developed a year later in one of these two patients, for which a further curettage followed by local liquid nitrogen treatment was performed. Overall, there were no cases of post-operative complications or metastases. The patients were assessed using the Musculoskeletal Tumour Society scoring system (MSTS) to determine limb function. The average score achieved was $94 \%$ (79\% to $100 \%)$.

Conclusion: Intralesional curettage is an effective treatment strategy for lowgrade intramedullary chondrosarcoma of long bones, with excellent oncological and functional results. Careful case selection with stringent clinical and radiographic follow-up is recommended.

\section{Key Words}

\section{Chondrosarcoma}

Intralesional curettage

Polymethylmethacrylate cement - PMMA 
Musculoskeletal Tumour Society Score - MSTS

Local recurrence

\section{Introduction}

Chondrosarcoma is the second most commonly occurring primary malignant bone tumour, with a peak incidence between the fourth and seventh decades of life $[1,2,3,4,5]$. These tumours were first described as a separate entity by Phemister in 1930 [6]. In adults, the pelvis, ribs, shoulder girdle, femur, and humerus are mainly affected, while in children, facial bones and the knee region are the main sites [7]. The majority of lesions arise centrally in normal bone, uncommonly in pre-existing benign cartilaginous tumours (secondary chondrosarcoma), and rarely in synovial chondromatosis or 'de novo' in the synovium $[1,8,9]$. They have a variable and often unpredictable outcome, ranging from slowly growing indolent lesions, to highly aggressive invasive sarcomas [10]. Authors link the prognosis to tumour size, anatomical location, and most importantly, histological grade $[10,11]$. Five to 10 year 
survival rates for patients with low-grade tumours range from 85 to $100 \%$, and from 20 to $40 \%$ for high-grade tumours $[10,11,12,13,14,15,16,17]$. The treatment of chondrosarcoma is primarily surgical because of its resistance to chemotherapy and irradiation $[1,16,18,19]$, and while there is a universal acceptance that high-grade lesions in the appendicular skeleton are best treated by wide surgical resection, the diagnosis and management of low-grade lesions remains a controversial issue [19]. Firstly, distinguishing intramedullary low-grade chondrosarcoma from enchondroma is difficult, particularly on needle core biopsy because of potential sampling issues [20]. Secondly, there is currently no consensus with respect to the optimal surgical treatment for these cases. Different methods reported in the literature include wide excision, marginal excision, and intralesional curettage. Some authors advocate wide excision, necessitating substantial reconstructive surgery, often requiring massive endoprostheses or allografts $[21,22]$. In contrast, many others believe that less extensive surgery is indicated for less aggressive lesions [5,13,19,23,24,25]. This would minimises the need for complex limb reconstruction and results in a good functional outcome. In this paper, we examine the oncological and functional outcomes of intralesional curettage and cementation as a treatment strategy.

\section{Patients and Methods}

Between 1999 and 2005, 39 consecutive patients with histologically verified low-grade intramedullary chondrosarcoma of long bones underwent intralesional curettage and cementation of their lesion at our institution. These patients were identified using our department's histopathology database and then were retrospectively reviewed. The inclusion criteria included a definitive histological diagnosis of grade 0.5 or 1 chondrosarcoma, intramedullary lesions arising in long bones, and a minimum follow- 
up of three years. We excluded patients with lesions breaching the bone cortex and/or associated with a soft tissue mass, as these were treated by wide excision. However, the longitudinal length of the lesion alone did not influence our decision to perform intralesional curettage. We obtained clinical data from the case notes, hospital databases, imaging studies, clinic reviews and patient questionnaires. There were 10 males and 29 females with a mean age of 55.5 years (range 32 to 82 ). The mean overall follow-up was 5.1 years (range 3 to 8.7). Patients were referred to our regional tumour centre and managed by a multidisciplinary team. All patients had persistent pain as one of the presenting features. Pre-operative imaging included plain radiographs, technetium (TC99) bone scans, chest CT and MRI. Imaging studies were evaluated by experienced musculoskeletal consultant radiologists for the presence of malignant features including significant endosteal scalloping (greater than two thirds of cortical thickness), sclerotic rim, reactive thickening of the cortex with bone expansion, cortical destruction, soft tissue extension and periosteal reaction $[26,27,28]$. All 39 patients had one or more of these features, and therefore, needle and/or open biopsies were obtained in all cases. The diagnosis of low-grade chondrosarcoma was reached combining radiological, histological and clinical findings. The patients included in this study underwent intralesional curettage of their lesion through a cortical window, followed by washout with saline pulsatile lavage then adjuvant treatment with bone cement. The resultant intraosseous defects were reconstructed with polymethylmethacrylate (PMMA) bone cement, as this provides immediate stability, avoids the morbidity of autogenous bone graft, and aids the post-operative radiographic evaluation for signs of local recurrence [24]. Eighteen lesions occurred in the femur, 14 in the humerus, 6 in the tibia, and 1 in the radius. Patients were followed up at regular intervals of 3 months in the first year post-operatively, and every 6 months between 1 and 3 years, and on an annual basis thereafter. Plain radiographs were obtained at each visit of the operated site and the chest to identify local recurrence and/or metastases. Clinical outcome assessment was performed using the 
Musculoskeletal Tumour Society (MSTS) scoring system for the upper and lower limbs [29]. This system assigns numerical values ( 0 to 5$)$ for each of the following six categories. In the upper limb: pain, function, emotional acceptance, hand positioning, dexterity, and lifting ability. In the lower limb: pain, function, emotional acceptance, ambulatory support, walking ability, and gait. A numerical score and a percentage rating are calculated to allow for comparison of results.

\section{Histological Grade}

Histology slides were examined for grade by experienced musculoskeletal consultant histopathologists. The histological grading system used at our Institution is a modified variant of the system first described by J affe in 1958 [30]. Characteristics of the cells and intercellular background, degree of pleomorphism and mitotic activity, changes in the matrix (from hyaline to myxoid), and the pattern of infiltration of normal trabecular bone are all carefully analysed. A grade of $0.5,1,2,3$ is assigned on the basis of the above criteria. Grade 0.5 in our system refers to a lesion that other authors have designated as a 'CLUMP' (Cartilagenous Lesions of Unknown Malignant Potential) or 'atypical' enchondroma [16,31]. Such lesions demonstrate increased cellularity, mild nuclear atypia typified as open nuclei but without prominent nucleoli, and binucleate cells. The presence of permeation of host lamellar bone by tumour, as described by Mirra et al [32], renders the lesion a grade 1. Mitoses are absent in both grade 0.5 and 1, but present in grades 2 and 3. (Fig. 1-a,b,c). In addition to showing histological borderline features of malignancy, grade 0.5 lesions also demonstrate atypical radiological characteristics $[30,31,32]$ and a progressive biological behaviour. In this series, there were 19 patients with grade 0.5 tumours, and 20 with grade 1 lesions.

\section{Results}

\section{Oncological Outcome}


One patient died at 3.5 years post-operatively of an unrelated cause (myocardial infarction). She had had a grade 1 tumour in her left proximal humerus. At her last follow-up (3 years), she was completely pain-free and had excellent shoulder function. No signs of recurrence were noted on plain radiography at the time of review. Two of the 39 patients $(5 \%)$ developed local recurrence within the first two years following index surgery. The first patient was a 60-year-old female with an original lesion in her right proximal humerus, which was curetted in 2003. This was found to be a grade 1 lesion. Eighteen months later, a new lesion was identified on MRI (Fig. 2) after the patient had re-presented with shoulder pain. This was curetted and PMMA cement applied. The patient remains well at 29 months after her second procedure with no signs of recurrence or metastatic disease. The second patient was a 65-year-old female who had a primary lesion in her left proximal tibia (Fig. 3a,b) curetted in late 2005. Histopathological examination revealed a grade 0.5 tumour. Post-operative imaging was satisfactory and did not show any obvious residual tumour. A year later, she developed pain around the operated site and repeat MRI showed a recurrent lesion in the proximal tibia (Fig. 3c). Chest CT and isotope bone scans did not reveal any metastases. The recurrent tumour was curetted and PMMA cement was used to reconstruct the resultant defect. She re-presented with the same symptom 10 months later. A further MRI revealed another local recurrence. This was curetted again and treated with liquid nitrogen. The histological grade was again 0.5. Overall, none of the 39 patients developed metastases or post-operative complications.

\section{Functional outcome}

The average MSTS score achieved in all 39 patients was $94 \%$ (79\% to $100 \%)$. The mean upper limb score was $96 \%$ (83\% to $100 \%)$, whereas the mean lower limb score was $91 \%(76 \%$ to $96 \%)$. All patients were able to perform activities relating to their 
daily living and occupation. Four patients (10\%) reported episodes of mild pain around the operation site, with only $2(5 \%)$ using analgesics on a regular basis.

\section{Discussion}

There is currently no universally accepted operative treatment for low-grade chondrosarcoma of long bones. Intralesional curettage, either alone or combined with local adjuvant treatments, marginal resection, and en bloc resection with biologic or endoprosthetic reconstruction are all described in the literature $[5,13,19,21,22,22,23,24,25]$.

In contrast, high-grade chondrosarcoma is almost always treated with wide excision achieved by either amputation, or resection of the tumour with limb salvage reconstruction $[1,12,16]$. The latter procedures are associated with high complication and morbidity rates, functional deficit, and carry a high financial cost. While these adverse factors are acceptable when treating a life-threatening sarcoma, they are not favoured when managing a slow-growing lesion with little risk of metastatic potential. The potential for local recurrence and metastases in low-grade chondrosarcoma is extremely low, with reported 5-year survival rates ranging from 85 to $100 \%$ following various treatment strategies $[10,11,12,13,14,15,16,17]$. Many authors have shown intralesional curettage to be an acceptable treatment in these cases, as it avoids the morbidity associated with the more radical surgical procedures, without jeopardising the outcome $[5,13,19,23,25]$. In one of these studies [19], the mean MSTS score following treatment was $90 \%$, highlighting the excellent functional results achieved, which may not be encountered following more radical surgery. In contrast, two other studies [21,22] reported a high incidence of local recurrence and metastases following intralesional surgery for low-grade chondrosarcoma, and recommended wide en bloc excision rather that curettage to treat these cases. However, both 
papers included patients with chondrosarcomas in the pelvis and axial skeleton in addition to long bones, and these non-appendicular sites have been associated with a worse prognosis than with tumours limited to the long bones $[2,18]$. Furthermore, patients with tumours of all histological grades were included in the second study. This may explain the poor outcome reported in both papers.

In broad terms, the important considerations to take into account when treating a lowgrade tumour are: the long-term oncological outcome, morbidity, incidence of complications, functional demands of the patient, and the durability of the procedure.

As shown in our data, we only had 2 cases (5\%) of local recurrence both developing within the first 2 years. One was in the grade 0.5 group and the other in the grade 1 group. However, comparison of post-operative MRI (Fig. 2c) with the original MRI study (Fig. 2b) prior to first curettage indicates that in at least 1 of the cases the 'recurrence' appeared to have been due to incomplete curettage and therefore represent residual disease rather than local recurrence. It should also be noted that the recurrent/residual lesions were radiographically occult, and therefore, in a clinical setting of suspected local recurrence, MRI is required to confirm the diagnosis. The recurrent lesions were curetted, and in the second case, liquid nitrogen was used. Interestingly, the recurrences were of a similar histological grade to the primary tumour in both cases. In contrast, other authors have reported histological grade progression in local recurrence [5,33]. This variation suggests that low-grade chondrosarcomas do not all behave in the same way clinically or radiologically $[5,16]$. No metastases or post-operative complications occurred in our series. This compares favourably with other studies $[5,13,19,23,24,25]$. 
From a functional point of view, our MSTS scores were $96 \%$ and $91 \%$ for the upper and lower limbs respectively. Similar results are difficult to achieve following wide excision, with or without endoprosthetic reconstruction.

The role of fluorine-18 fluorodeoxyglucose positron emission tomography (FDG $\mathrm{PET}$ ) as a criterion for differentiating low-grade from high-grade chondrosarcomas is open to debate. A number of authors believe it is a valuable adjunct in identifying aggressive cartilage lesions, directly in primary and locally recurrent sites, or indirectly on whole-body scans by detecting unsuspected metastases [34]. However, others have shown that although high-grade chondrosarcomas have a higher glucose metabolism than do low-grade cartilage tumors, the measurement of glucose metabolism by positron emission tomography alone cannot fully distinguish between benign and low-grade malignant cartilaginous tumours [35].

\section{Conclusion}

This study supports the view that intralesional curettage is an effective treatment strategy for low-grade chondrosarcoma of long bones, with excellent oncological and functional results. We propose that this treatment option is a rational alternative to more radical procedures, as it preserves function, has low morbidity, is cost effective, and does not appear to have an adverse effect on long-term outcome. Careful patient selection with stringent clinical and radiographic follow-up is crucial for the successful management of patients in this way.

\section{Conflict of interest}

The authors declare that they have no conflict of interest. 


\section{References}

1. Casali P, Santro A. Malignant bone tumour other than osteosarcoma and Ewing's sarcoma. Oxford Text Book of Oncology. Oxford University P ress; 1995: $1977-78$

2. Dahlin DC, Henderson ED. Chondrosarcoma, a surgical and pathological problem; review of 212 cases. J Bone Joint Surg Am. 1956; 38: 1025-1038

3. Healey J H, Lane J M. Chondrosarcoma. Clin Orthop Relat Res. 1986; 204: $119-129$ 
4. Unni KK. Bone tumours: general aspects and data on 11,087 cases. Dahlin's Bone Tumours. Philadelphia, PA: Lippincott-Raven; 1996: 71-72

5. Leerapun $T$, Hugate RR, Inwards $C$, et al. Surgical management of conventional grade I chondrosarcoma of long bones. Clin Orthop Relat Res. 2007; 463: 166-172

6. Phemister DB. Chondrosarcoma of Bone. Surgery, Gynecology and Obstetrics. 1930; 50, 216

7. Huvos AG, Marcove RC. Chondrosarcoma in the young. A clinicopathologic analysis of 79 patients younger than 21 years of age. Am J Surg Pathol. 1987 Dec;11(12):930-42

8. Kindblom LG, Angervall L. Myxoid chondrosarcoma of the synovial tissue. A clinicopathologic, histochemical, and ultrastructural analysis. Cancer. 1983 Nov 15;52(10):1886-95

9. Bertoni F, Unni KK, BeaboutJ W, et al. Chondrosarcomas of the synovium. Cancer. 1991 J an 1;67(1):155-62

10. Sanerkin NG, Gallagher PA. A review of the behaviour of chondrosarcoma of bone. J Bone Joint Surg Br. 1979; 61: 395-400

11. Evans HL, Ayala AG, Romsdahl MM. Prognostic factors in chondrosarcoma of bone: a clinicopathologic analysis with emphasis on histologic grading. Cancer. 1977; 40: 818-831

12. Fiorenza F, Abudu A, Grimer RJ , et al. R isk factors for survival and local control in chondrosarcoma of bone. J Bone Joint Surg Br. 2002; 84: 93-99

13. Bauer HC, Brosjo O, Kreicbergs A, et al. Low risk of recurrence of enchondromas and low-grade chondrosarcoma in extremities: 80 patients followed for 2-25 years. Acta Orthop Scand. 1995; 66: 283-288

14. Bergh P, Gunterberg B, Meis-Kindblom J M, et al. Prognostic factors and outcome of pelvic, sacral, and spinal chondrosarcomas: a centre based study of 69 cases. Cancer. 2001; 91: 1201-1212 
15. Donati D, EI Ghoneimy A, Bertoni F, et al. Surgical treatment and outcome of conventional pelvic chondrosarcoma. J Bone Joint Surg Br. 2005; 87: 15271530

16. Lee FY, Mankin HJ , Fondren G, et al. Chondrosarcoma of bone: an assessment of outcome. J Bone Joint Surg Am. 1999; 81: 326-338

17. Van Loon CJ, Veth RP, Pruszynski M, et al. Chondrosarcoma of bone: oncological and functional results. J of Surg Oncol. 1994; 57: 214-221

18. Eriksson Al, Schiller A, Mankin $\mathrm{HJ}$. The management of chondrosarcoma of bone. Clin Orthop Relat Res. 1980; 153: 44-66

19. Ahlmann ER, Menendez LR, Fedenko AN, et al. Influence of cryosurgery on treatment outcome of low-grade chondrosarcoma. Clin Orthop Relat Res. 2006 Oct; $451: 201-7$

20. Marco RA, Gitelis S, Brebach GT, et al. Cartilage tumors: evaluation and treatment. J Am Acad Orthop Surg 2000 Sep-Oct; 8(5): 292-304

21. Tsuchiya $H$, Ueda $H$, Morishita $H$, et al. Borderline chondrosarcoma of long and flat bones. J Caner Res Clin Oncol. 1993; 119: 363-368

22. Ozaki T, Lindner N, Hillmann A, et al. Influence of intralesional surgery on treatment outcome of chondrosarcoma. Cancer. 1996; 77: 1292-7.

23. Schreuder HW, Pruszczynski M, Veth RP, et al. Treatment of benign and lowgrade malignant intramedullary chondroid tumours with curettage and cryosurgery. Eur J Surg Oncol. 1998; 24: 120-126

24. Yasko AW. Treatment of low-grade chondrosarcoma. Current Opinion in Orthopaedics. 2000; 11: 471-478

25. Yasko AW, Coufal C, Ayala AG, et al. Low-grade chondrosarcoma of long bones: late results of curettage versus resection. $65^{\text {th }}$ Annual Meeting of the American Academy of Orthopaedic Surgery, New Orleans, LA, March 19-23, 1998. 
26. Murphey MD, Flemming DJ , Boyea SR, et al. Enchondroma versus chondrosarcoma in the appendicular skeleton: differentiating features. Radiographics. 1998; 18: 1213-1237

27. Wang XL, Beuckeleer LH, Schepper AM, et al. Low-grade chondrosarcoma vs enchondroma: challenges in diagnosis and management. Eur Radiol. 2001; 11: 1054-1057

28. Kendell SD, Collins MS, Adkins MC, et al. Radiographic differentiation of enchondroma from low-grade chondrosarcoma in the fibula. Skeletal Radiol. 2004; 33: 458-466

29. Enneking WF, Dunham W, Gebhardt MC. A system for the functional evaluation of reconstructive procedures after surgical treatment of tumors of the musculoskeletal system. Clin Orthop Relat Res. 1993; 286: 241-6

30. J affe HL. Tumors and tumorous conditions of the bones and joints. Philadelphia, Lea \& Febiger, 1958, pp. 270 and 326-328

31. Grimer RJ , Carter SR, Tillman RM, et al. Chondrosarcoma of bone. The Orthopaedic Forum, J Bone Joint Surg Am. 2000; 82-A: 1203-04

32. Mirra J M, Gold R, Downs J, et al. A new histologic approach to the differentiation of enchondroma and chondrosarcoma of the bones. A clinicopathologic analysis of 51 cases. Clin Orthop Relat Res. 1985; 201: 21437

33. Scwab J H, Wenger D, Unni K, et al. Does local recurrence impact survival in low-grade chondrosarcoma of the long bones? Clin Orthop Relat Res. 2007; 462: $175-180$

34. Feldman F, Van Heertum R, Saxena C, et al. 18FDG-PET applications for cartilage neoplasms. Skeletal Radiol. 2005 J ul;34(7):367-74. E pub 2005 J un 4

35. Lee FY, Yu J, Chang SS, Fawwaz R, et al. Diagnostic value and limitations of fluorine-18 fluorodeoxyglucose positron emission tomography for 
cartilaginous tumors of bone. J Bone Joint Surg Am. 2004 Dec;86-

$A(12): 2677-85$

Figure Legends

Figure 1 (a) Normal Cartilage. (b) Grade 0.5 Chondrosarcoma, showing

clustering of chondrocytes, increased cellularity, and mild nuclear atypia. (c) Grade 1

Chondrosarcoma, showing the above changes in addition to entrapment of host lamellar bone. No mitotic activity seen.

Figure 2 Local recurrence in a patient with previous curettage and cementation for a grade 1 chondrosarcoma of the proximal humerus. Axial TIW SE MR image demonstrates the signal void due to the cementoma (black arrowheads) and the recurrent tumour (black arrow). 
Figure 3 Residual tumour in a patient treated for grade 0.5 chondrosarcoma of the proximal tibia.

(a) Pre-operative lateral radiograph demonstrates a heavily calcified lytic lesion (arrows) in the proximal tibia.

(b) Pre-operative axial fat suppressed T2W FSE MR image at the level of the tibial tuberosity shows the transverse extent of the lesion (arrows).

(c) Post-operative axial fat suppressed T2W FSE MR image at the level of the tibial tuberosity shows the position of the cementoma (black arrowheads) and the residual tumour (white arrows). 


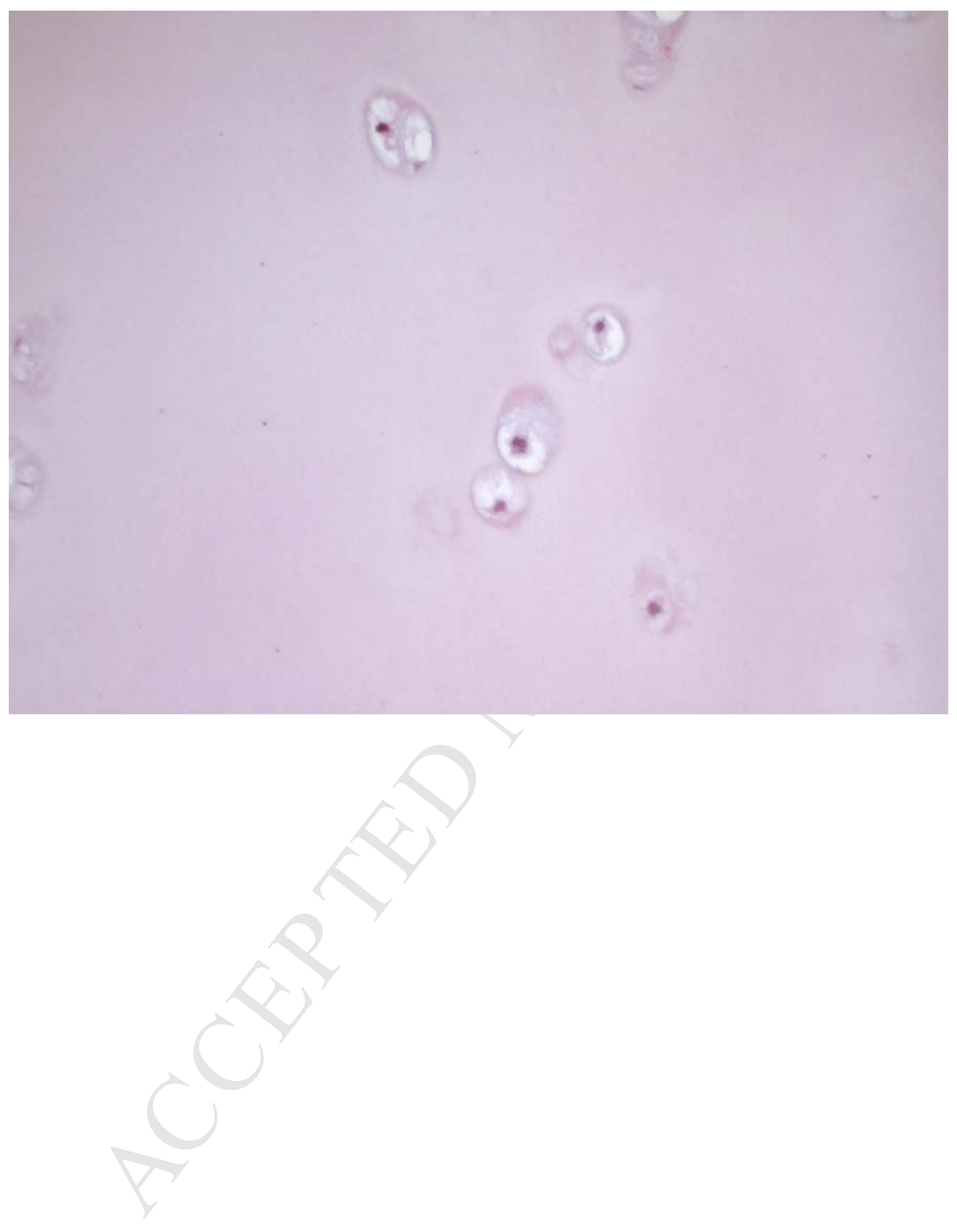




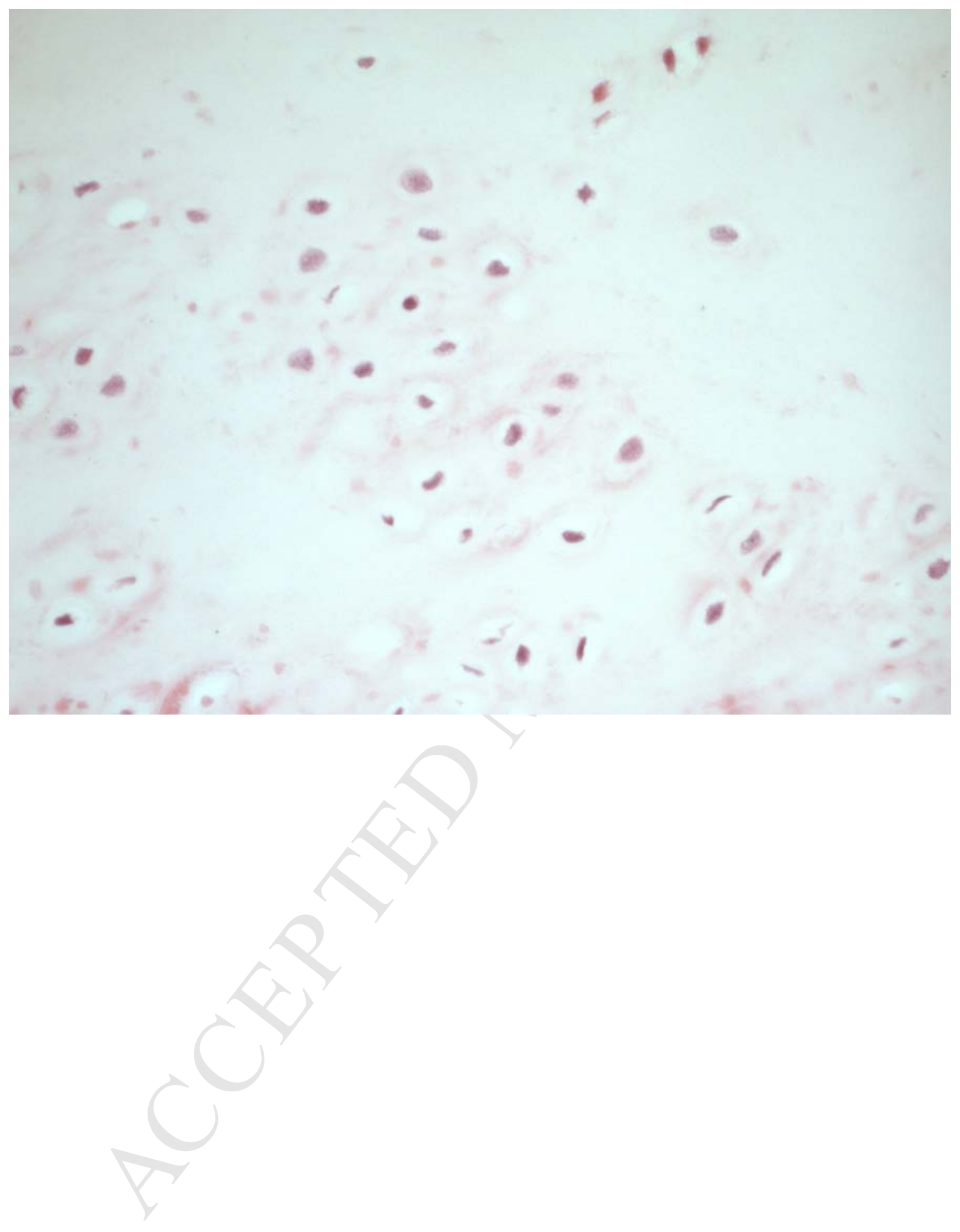




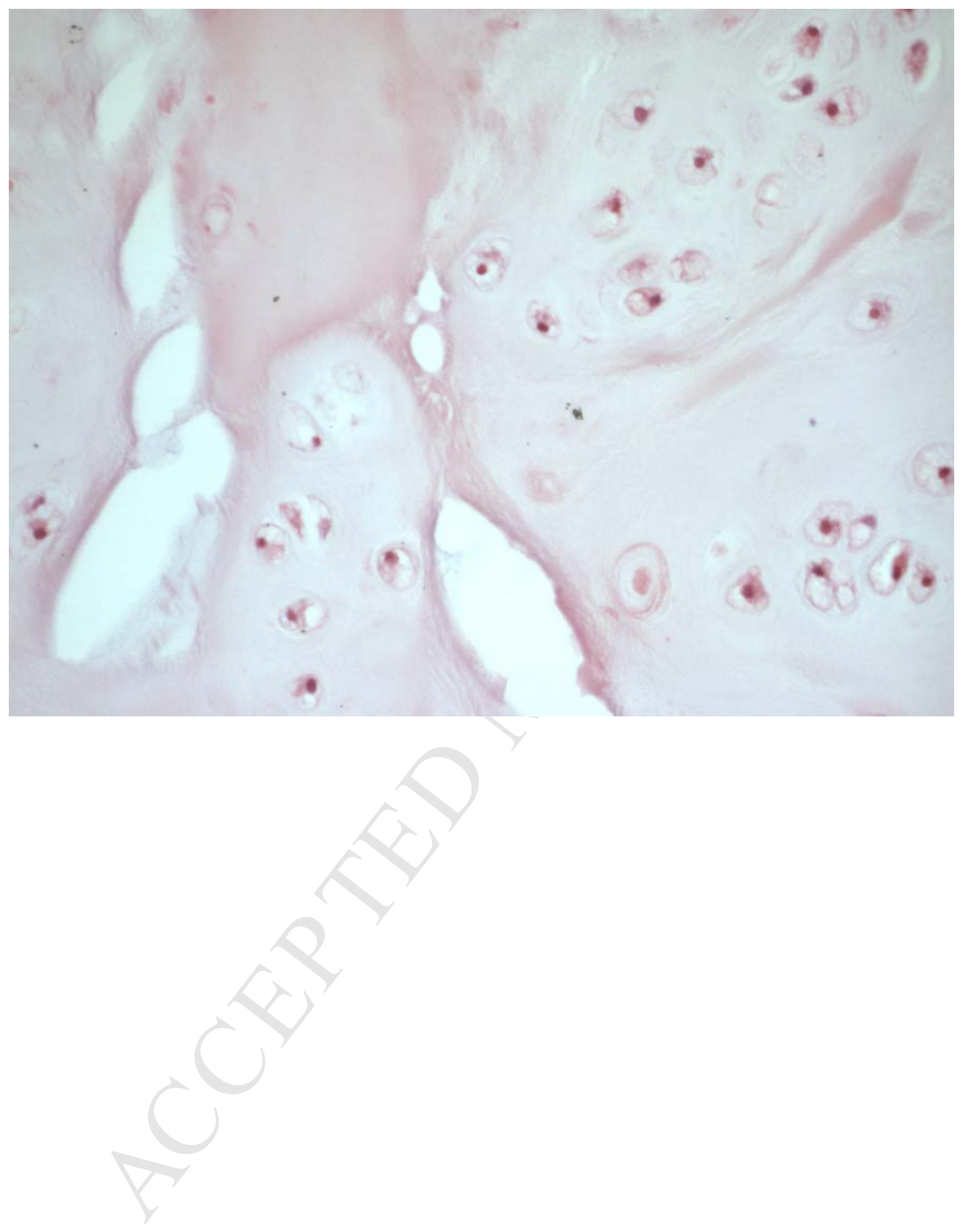




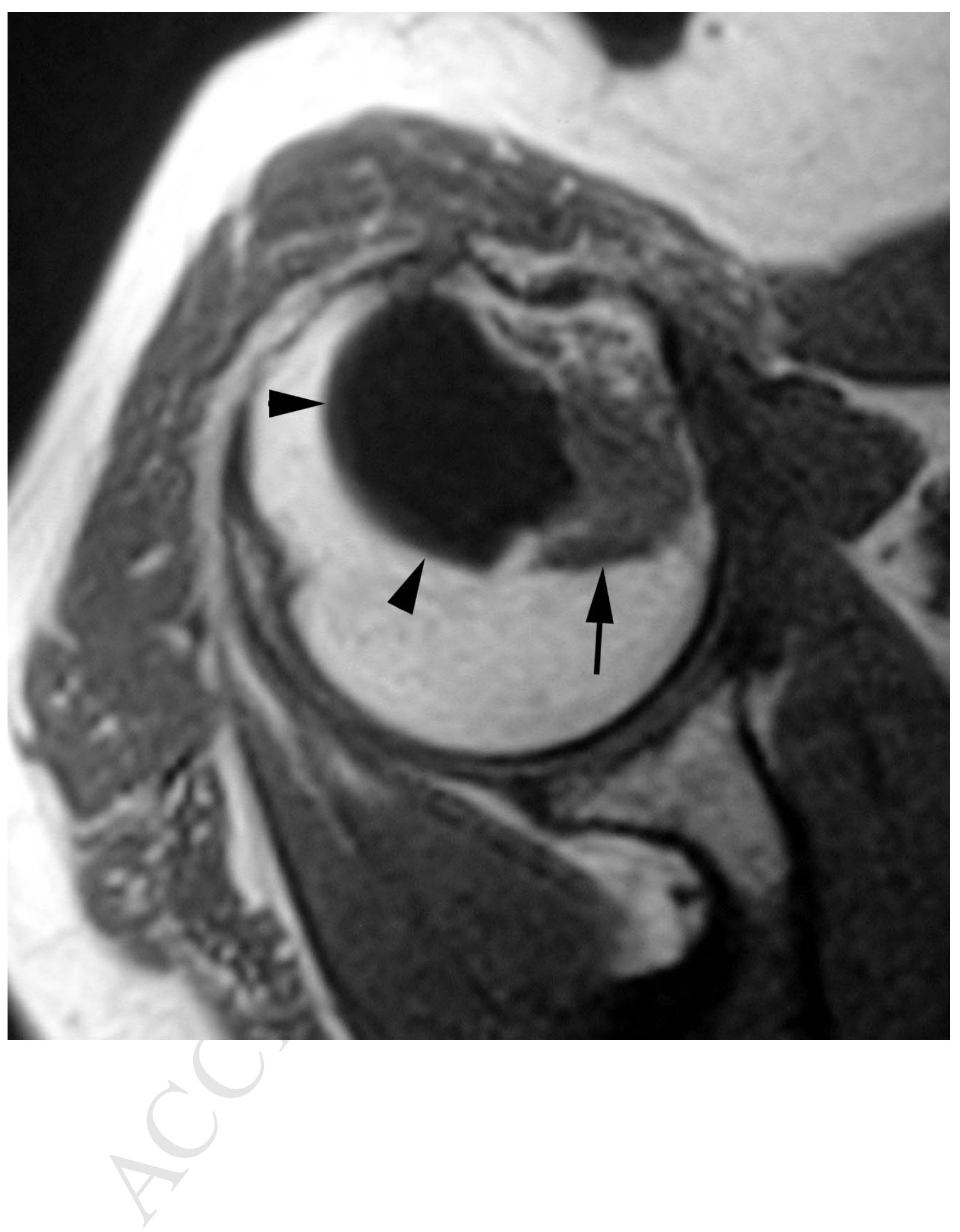




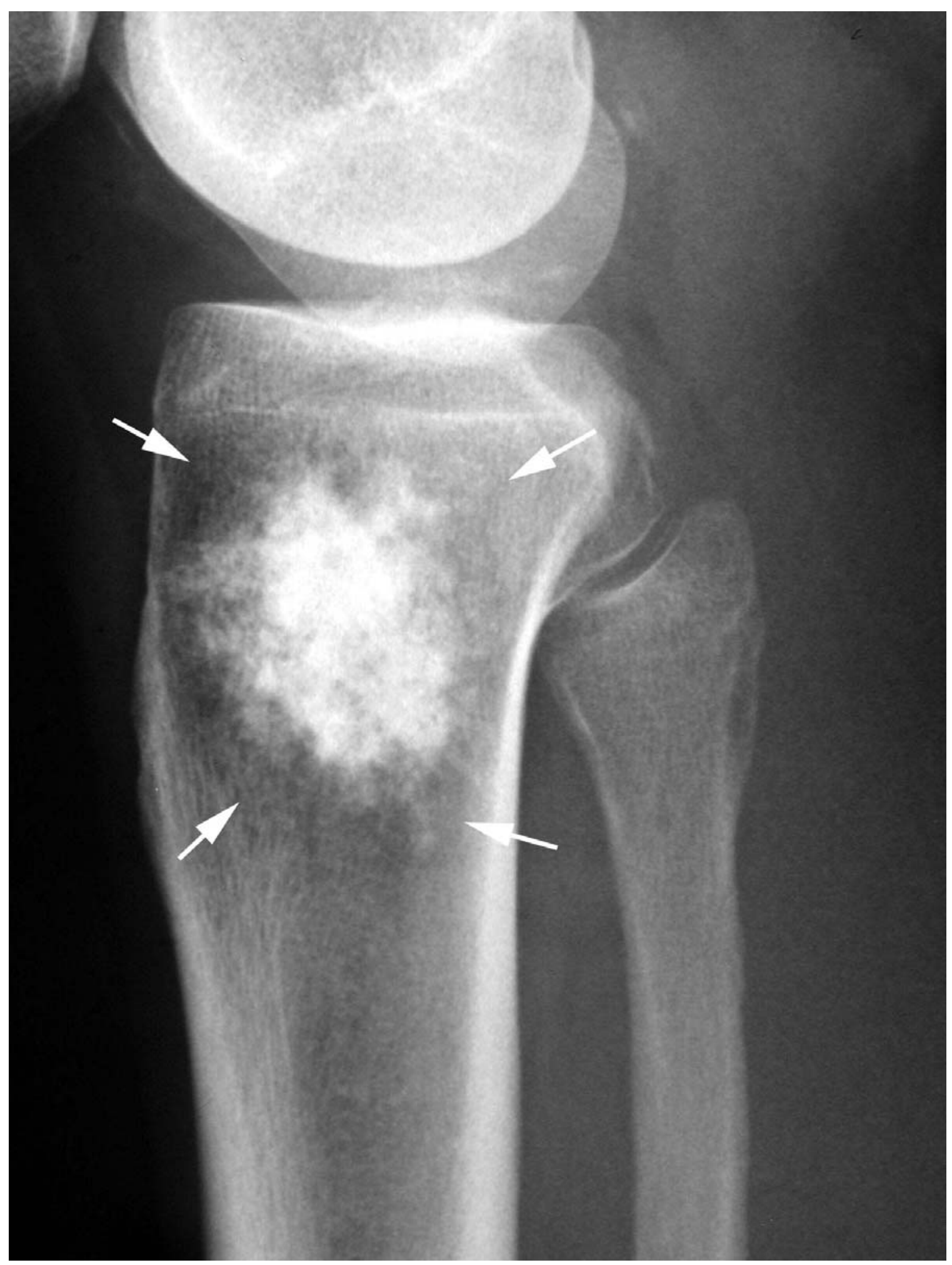




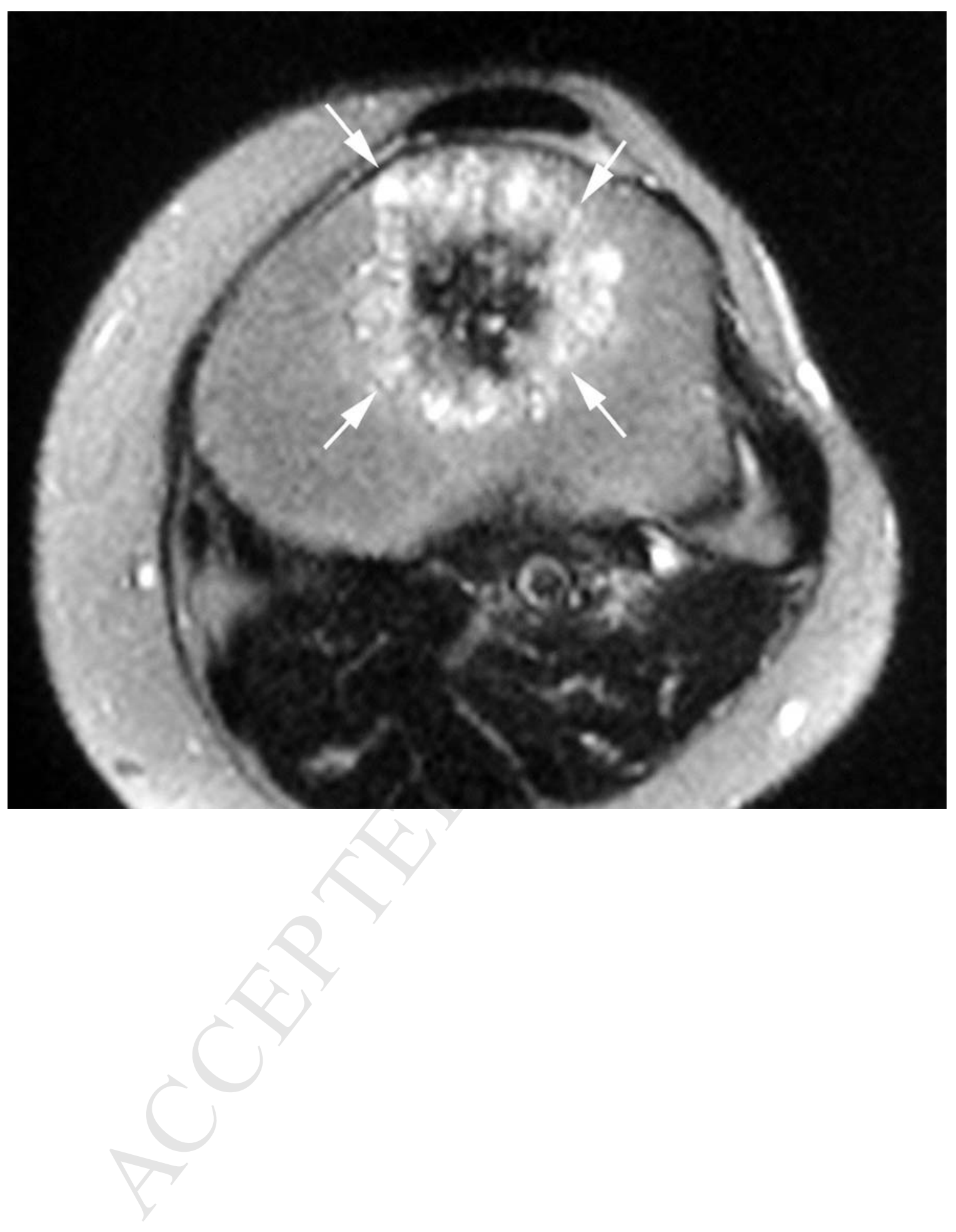




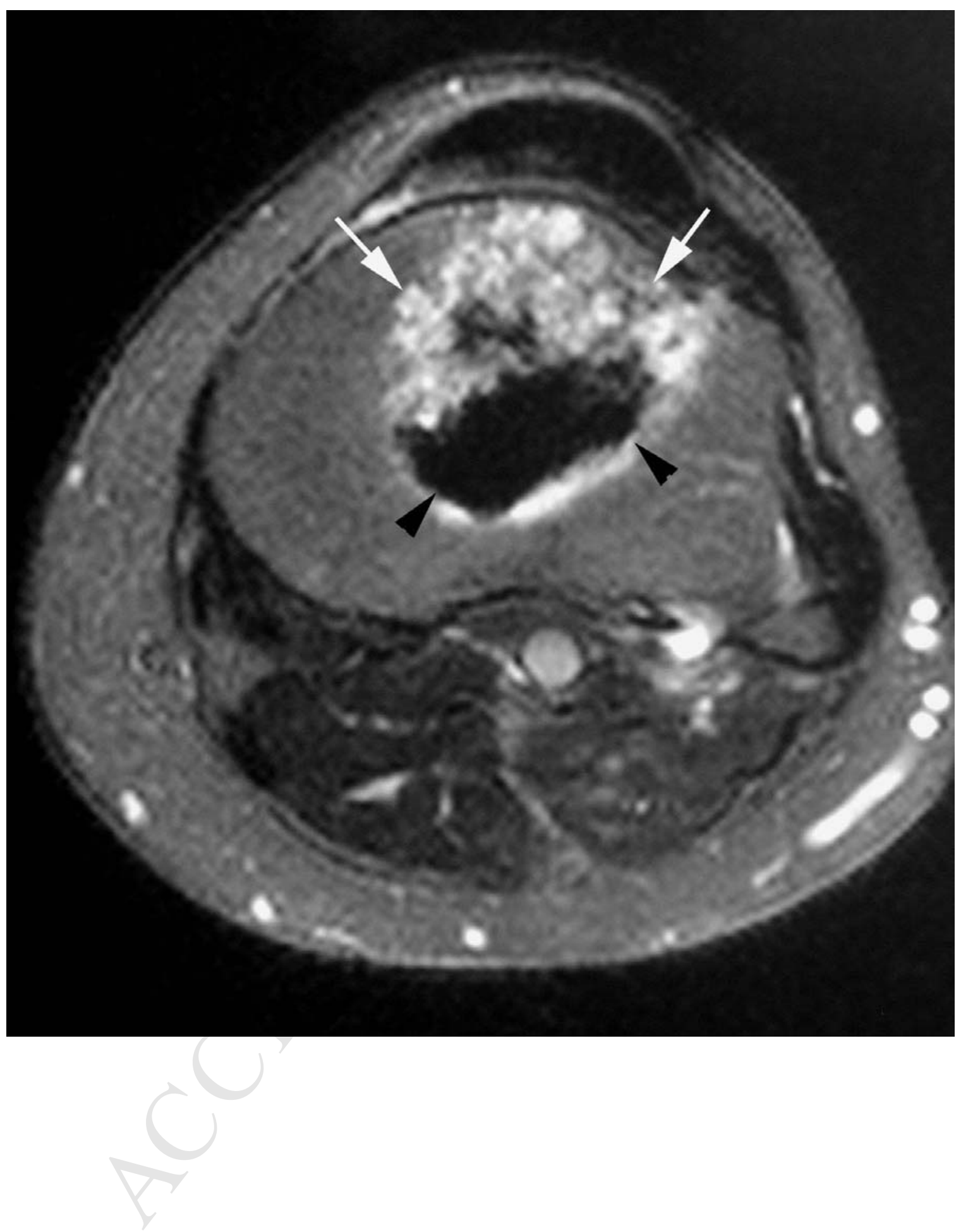

